\title{
Safety Signs Perception and Adoption with the ISO and ANSI Standards
}

\author{
Amir Hossein Davoudian Talab, ${ }^{1}$ and Gholam Reza Azari ${ }^{2,}{ }^{*}$ \\ ${ }^{1}$ Department of Occupational Hygiene, Behbahan Faculty of Medical Sciences, Behbahan, Iran \\ ${ }^{2}$ Department of Basic Sciences, University of SocialWelfare and Rehabilitation Sciences, Tehran, Iran \\ "Corresponding author: Gholam Reza Azari, Assistant Professor, Department of Basic Sciences, University of SocialWelfare and Rehabilitation Sciences, Tehran, Iran. E-mail: \\ azarigh@yahoo.com \\ Received 2017 May 09; Revised 2017 June 03; Accepted 2017 July 11.
}

\begin{abstract}
Background: One way of controlling hazards in the work environment is a use of safety signs. Safety signs are among the safe information group; hence, if these signs are not understood properly it could cause an injury or even death.

Objectives: The aim of this study is surveying perception of safety signs and adoption with ISO and ANSI standards.

Methods: This cross-sectional study was conducted during 2013 to 2014 in the 3 provinces of Khuzestan, Fars, and Tehran. The study population included 370 non-monochromatic employees working in the industries. For collecting information, the standard questionnaire of the international organization for standard (ISO 9186-1) and demographic information was used. A total of 13 safety signs were utilized for determination of perception. Stratified - Random sampling method was used, then, the obtained data were utilized using SPSS-16 software and applying descriptive statistics.

Results: In this study, the overall rate of perception of safety signs was 78.4\% with a standard deviation of $15.1 \%$. The lowest percentage of perception was related to the sign "face shield must be worn" (53.5\%). In the assessment of safety signs based on ANSI Z5353 and ISO $9186-1$ standard, $62.5 \%$ and $69.2 \%$ of signs can be reached to limit of acceptable perception.

Conclusions: The perception patterns of safety signs are different. Assessing perception of signs show a moderate level of perception in accordance with ISO standard; however, to reach ANSI standard, implementation of intervention programs (Judgment test) is suggested due to perceptual adaptation with target population and redesign of sign with low perception.
\end{abstract}

Keywords: Safety, Sign, Perception

\section{Background}

Safety signs are among safe information group, which is defined as follows: a safety sign is a graphical form that expresses a general safety message (1). All people during their daily lives are faced with many signs and symbols, of which, stands and safety signs can be mentioned. In general, today, use of safety and warning signs has become an integral part of life (2). In addition, graphical symbols that are an integral part of warning signs have a lot of features including: high ability to create connections with concepts and directions, solving problem of unfamiliarity with the language and lack of sufficient skills in reading, as well as a better durability in memory than text (3).

Another positive feature of signs is that they make a necessary potential for reading and understanding in different groups and different language backgrounds. For example, there are more than 25 official languages only in the European Union (4). However, nowadays, we see that some of these signs are not well understood and defects are seen more in adults than younger people (5). In addition, sometimes these signs can have a different message or it may deliver exactly opposite of its original concept (6), due to the fact that the perception of a fixed sign in different coun- tries cannot be the same $(7,8)$. The issue is very important in terms of safety. If the signs are not understood correctly, it may cause an injury or even the death of an individual (3). The American national association pointed out the defects in the accurate notification through safety signs as the 3rd most common factor of accident investigation (9) and the use of safety signs is the 4 th common method of accident and injury prevention (6).

In general, safety signs may represent a danger, dangerous conditions, or consequences of being exposed to danger. Furthermore, some signs include caution and safety recommendations for the individuals who execute unsafe and dangerous behaviors; however, at the same time, it may show a way in preventing such behaviors (10).

The studies showed that safety signs have to be evaluated regarding their correct comprehension by people before use (11). However, some studies have shown a poor perception of the safety signs (5).

Liu referred to some of the criteria for the evaluation of the safety signs as follows: the good announcing, readability, understandability, and ease of learning (4). However, this criterion, as well as other similar criterias, do not have the quantification ability or might have low quantification ability. In this study, standard (ISO 9186-1: 2007) will 
be used as the standard method for quantification of the perception of safety signs (12). Thus, the staff's familiarity with these signs is great importance in order to have a correct understanding of the signs and their responsibilities in case of being exposed to dangers (10).

\section{Objectives}

The aim of this study is surveying perception of safety signs and adoption with ISO and ANSI standards as well as present strategies for improving their comprehensibility.

\section{Methods}

This cross-sectional study was conducted during 2013 to 2014 in the 3 provinces of Khuzestan, Fars, and Tehran. The 3 provinces were selected based on a sampling of industrial regions in the north and south of the country. The study population included 370 non-monochromatic employees working in the industries. Industries were selected based on the researchers' opinion. Thus, in the Khuzestan province, the petrochemical industry was selected. In the Fars province, the rubber industry was selected, and in the Tehran province, the pharmaceutical manufacturing industry, perfumery, as well as pen industries were selected. The workers were selected by the stratified-random sampling method using a random number table. Data were collected using the questionnaire of perception test of safety signs, international organization for standardization (Iso9186-1.2007) (12), and its validity was confirmed by experts in ergonomics and safety in Shiraz University (10). This questionnaire contains 4 parts: 1 , instruction sheet for explaining how to properly complete the questionnaire; 2 , demographic data sheet, including age, sex, work experience, education level, work experience, education, and shift work; 3, example sheet, this part contains an example; and 4, test sheet of safety signs (13 types of color safety sign of the adhesive back $8 \times 8 \mathrm{~cm}$ in size are attached on 13 white A4 sheets). Each A4 sheet contains a type of sign. There are 13 signs used in this study ( 6 obligatory signs, 2 signs related to safe conditions, 2 warning signs, 2 prohibition signs, and 1 fire signs).

In accordance with the clause of 4.2.6 of the standard, a number of signs in each test should not be more than 15 PCs, as well as the size of signs according to clause of 6.2.3 standard, $8 \times 8 \mathrm{~cm}$, and colored with the adhesive back for sticking to white A4 sheet (13).

Determination of the size and composition of signs is based on the number of the signs available in a particular industry where the workers are in contact with daily. In addition, in this study, we tried using similar signs among all industries in order to determine factors associated with the amount of perceived safety signs. After giving the questionnaires to each of the users, they were asked to, after visiting the signs, mention their perception of sign as well as do one thing after seeing the sign. Next, after completing the questionnaires, according to standard method ISO 9186-1: 2007, responses were divided into 5 groups: true, false, false and conversely, I do not know, and no response. Then they were analyzed. The number of people who responded correctly, were known as understanding that sign to an extent. Furthermore, in the evaluation of the extent of understanding, the average of correct answers on safety signs, according to the standard ISO9186-1: 2007, is 67\%, which means that $67 \%$ of participants in the test can give a correct answer to the sign (12). In addition, in assessing the extent of the perception of safety signs in accordance with standard proposed by ANSI Z5353 (standard of the American national standards institute), the minimum average of correct answers on the safety signs is $85 \%$ (meaning the sign that $85 \%$ of participants would give the correct answer of the sign's concept, is considered as a good sign and with high understandability) (14).

Also, according to clause 6.3.2 of the standard ISO9186$1: 2007$, the number of individuals participating in the testing has been expressed to be a minimum of 50 persons for each country. In this study, the confounding variable of the results in this study is provided by previous studies done in the field of perception of safety signs. The inclusion criteria in this study, according to the standard were the age range of 15 - 55 years (due to avoid entering the stage of aging and reduced cognitive ability) as well as a lack of color blindness. To test color blindness, Ishihara's color blindness test was used. Data were analyzed using the SPSS version 16 .

\section{Results}

In this study, 370 people were selected as the sample, of which $85.1 \%$ were male and $14.7 \%$ were female. In addition, all of them were at an age range of 15 - 60 years old, 35.2\% of the samples had a degree lower than a diploma, $35 \%$ had diploma degree, and 29.7\% had a bachelor's degree. In this study, as shown in Figure 1, the overall rate of perception of safety signs was $78.4 \%$ with a standard deviation of $15.1 \%$. The highest percentage of perception was related to the sign "use of safety gloves" (91.7\%) and the sign "no smoking" (95.4\%). The least rate of perception of safety signs was related to "the risk of toxic substances" (S13) and safety sign "face shield must be worn when operating" (S2), respectively, with a rate of perception of $27.5 \%$ and $39.2 \%$, related to Fars (Rubber industries) and Tehran (Perfumes, pen, and 


\begin{tabular}{|c|c|c|c|c|c|c|c|c|c|c|c|c|c|}
\hline Safety Sign & ID & \multicolumn{2}{|c|}{ Correct } & \multicolumn{2}{|c|}{ Wrong } & \multicolumn{2}{|c|}{ False and Opposite } & \multicolumn{2}{|c|}{ Don't Know } & \multicolumn{2}{|c|}{ No Answer } & \multirow{2}{*}{ ISO } & \multirow{2}{*}{ ANSI } \\
\hline & & $\mathbf{N}$ & Percent & $\mathbf{N}$ & Percent & $\mathbf{N}$ & Percent & $\mathbf{N}$ & Percent & $\mathbf{N}$ & Percent & & \\
\hline & S1 & 170 & 57.6 & 79 & 26.8 & 3 & 1 & 43 & 6.1 & & & $x$ & $x$ \\
\hline & S2 & 200 & 53.5 & 120 & 32.1 & 2 & 0.5 & 36 & 9.6 & 16 & 4.3 & $x$ & $x$ \\
\hline & S3 & 343 & 91.7 & 21 & 5.6 & 1 & 0.3 & 5 & 1.3 & 16 & 4.3 & $\checkmark$ & $\checkmark$ \\
\hline & S4 & 329 & 88 & 25 & 6.7 & 1 & 0.4 & 15 & 4 & 4 & 1.1 & $\checkmark$ & $\checkmark$ \\
\hline & S5 & 325 & 84.9 & 20 & 5.3 & - & - & 22 & 5.9 & 7 & 1.9 & $\checkmark$ & $\checkmark$ \\
\hline & S6 & 279 & 74.6 & 37 & 9.9 & 4 & 1.1 & 45 & 12 & 9 & 2.4 & $\checkmark$ & $\times$ \\
\hline & S7 & 241 & 64.4 & 60 & 16 & 9 & 2.4 & 54 & 14.4 & 10 & 2.7 & $x$ & $x$ \\
\hline & S8 & 142 & 85.5 & 21 & 12.7 & - & - & 4 & 1.8 & - & - & $\checkmark$ & $\checkmark$ \\
\hline & S9 & 336 & 89.8 & 14 & 3.7 & - & - & 8 & 2.1 & 16 & $4 / 3$ & $\checkmark$ & $\checkmark$ \\
\hline & S10 & 328 & 87.7 & 12 & 3.2 & - & - & 27 & 7.2 & 7 & $1 / 9$ & $\checkmark$ & $\checkmark$ \\
\hline & S11 & 330 & 88.2 & 17 & 4.5 & 4 & 1.1 & 15 & 0.4 & 8 & $2 / 1$ & $\checkmark$ & \\
\hline & S12 & 189 & 95.4 & - & - & - & - & 9 & 4.5 & - & - & $\checkmark$ & $\checkmark$ \\
\hline & S13 & 113 & 56.2 & 37 & 4.18 & - & - & 51 & 25.4 & - & - & $x$ & $x$ \\
\hline Mean & & 255.7 & 78.4 & 35.6 & 10.1 & 1.8 & 0.5 & 25.6 & 7.2 & 7.1 & 2.2 & 69.2 & 61.5 \\
\hline SD & & 83.6 & 15.1 & 32.9 & 9.6 & 2.6 & 0.7 & 18.1 & 6.8 & 6.2 & 1.6 & & \\
\hline
\end{tabular}

Figure 1. Safety Sign Perception and Adoption of Standards

pharmaceutical industries), respectively as shown in Figure 2. The overall rate of perception of safety signs, according to ANSI Z5353 and ISO9186 standards, was respectively $62.5 \%$ and $69.2 \%$. Figure 2 also shows the rate of perception and rate of compliance of the safety signs with the standard according to location of the industry under study, therefore, the results showed that the highest rate of compliance with the ANSI Z535.3 and ISO3864 standards was respectively $92 \%$ and $76 \%$ related to the petrochemical industry in Khuzestan province. 


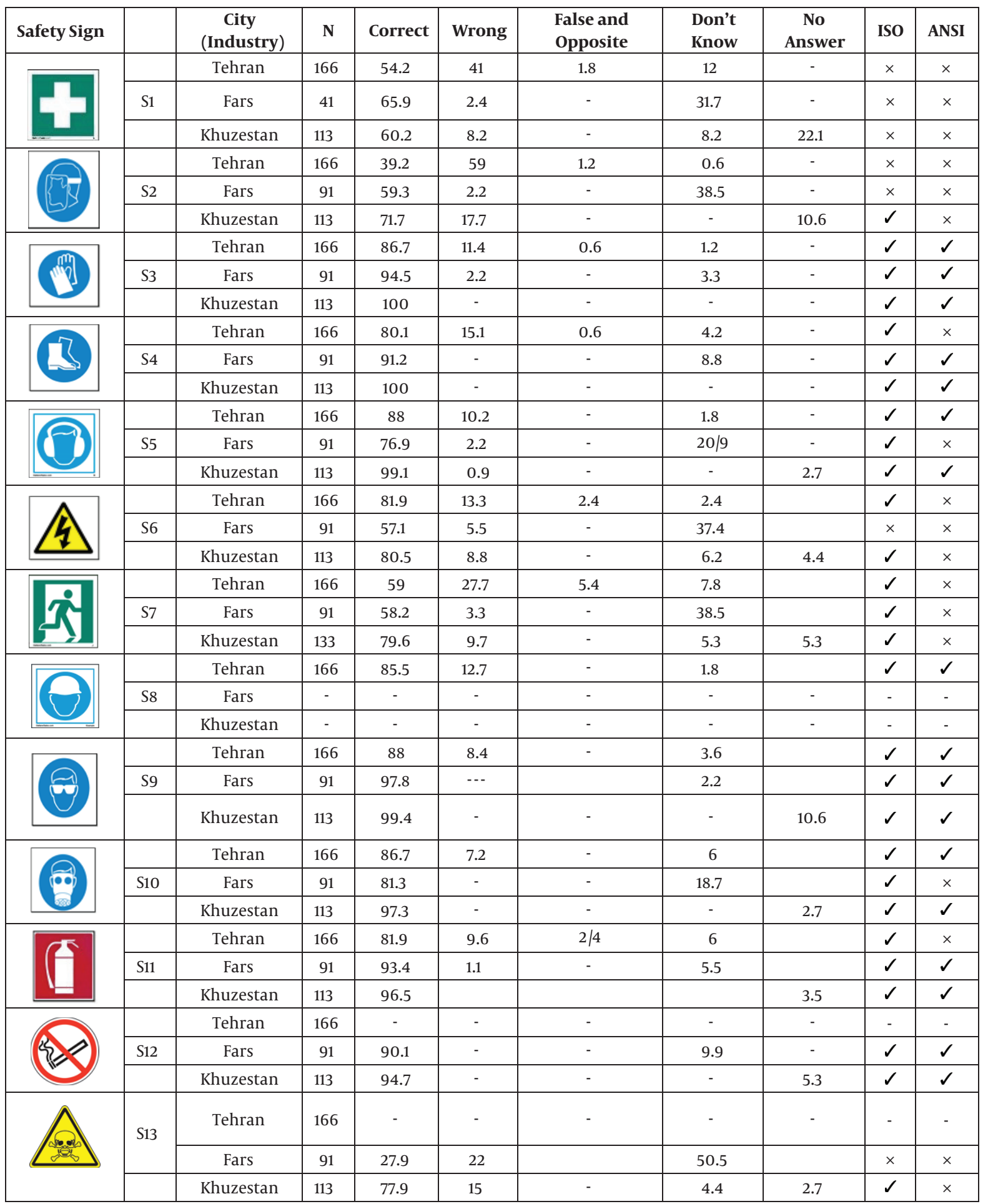


Table 1. Demographic Data of Sample

\begin{tabular}{|c|c|c|}
\hline Variable & Number & Percent \\
\hline \multicolumn{3}{|l|}{ Sex } \\
\hline Male & 313 & 85.3 \\
\hline Female & 54 & 14.7 \\
\hline \multicolumn{3}{|l|}{ Education } \\
\hline Under diploma & 129 & 35.2 \\
\hline Diploma & 228 & 35 \\
\hline BS & 109 & 29.8 \\
\hline \multicolumn{3}{|l|}{ Shift work } \\
\hline Day & 328 & 94.5 \\
\hline Night & 19 & 5.5 \\
\hline
\end{tabular}

\section{Discussion}

The results of the study showed that the overall average rate of a correct perception of safety signs in the sample was $78.4 \%$ with a standard deviation of 15.1 , the lowest amount of perception was related to use of face shield (53\%), which most wrong answers were also related to the same signs (32.1\%). A similar study was the Liu study, which showed the rate of perception of safety signs in China (32.2\% and SD of 30.3) and a rate of perception of $42.7 \%$ and SD of 36.3 in Germany (4).

Chan et al. obtained average perceptions of $63.08 \%$ (SD $=28.41$ ) in the American people and showed that the overall average perception of the safety signs in Hong Kong and Korea was $20.47 \%$ and $21.94 \%$, respectively (11). A study conducted by Zamanian et al. showed the overall average correct perception to be $70.94 \%(S D=27.38)$. These studies have shown that high standard deviation in this study and similar studies indicate differences in perception of safety signs as well as a different pattern of perception of safety signs (9). In addition, in various countries, the rate of perception of safety signs is different. These differences are due to the differences in cultural background (15), how to display safety signs and graphic symbols (16), as well as ways of thinking in different societies (11) that cause this change in the perception rate of the safety signs in different countries. In order to assess the level of compliance of the perception of safety signs with standard ANSIZ5353, the American national standards institute (ANSI), $62.5 \%$ of signs could reach an acceptable level of perception according to ANSIZ5353. This amount in Zamanian et al.'s study was $50 \%$ (9), in Liu's study in Germany was $18.75 \%$, and in China was $18.75 \%$ (4). In the study conducted by Annie et al., 30\% of all signs studied had at least an average perception according to the standard ANSIZ5353 (17). In the study done by Shinar et al., the overall rate of perception among drivers was $40 \%$ and they received only $17 \%$ of total signs of limit permitted by standard ANSIZ5353 (8). In order to assess the level compliance of safety signs with the standard ISO9186, in this study $69.2 \%$ of the samples reached an acceptable standard (3), while in the study conducted by Moradi et al. (13), 44\% samples were able to reach an acceptable standard ISO3864 (18). In the study conducted by Chan et al., in assessing the perception of signs by the American people, $50 \%$ of the samples reached an acceptable standard, while in the population of Hong Kong and Korea only $8.33 \%$ samples could reach an acceptable standard ISO3864 (11). In assessing perception rate of safety signs in provinces separately, $76 \%, 46 \%$, and $42 \%$ of the safety signs, respectively, in provinces of Khuzestan, Tehran, and Fars could obtain acceptable limit of the standard ANSI Z535.3. Similarly, 92\%, 63\%, and 59\% of safety signs, respectively, in the provinces of Khuzestan, Tehran, and Fars could obtain acceptable limit of the standard ISO. In more than $80 \%$ of safety signs, the Khuzestan province, in which target population was petrochemical workers, had a high level of perception of safety signs. This could be due to differences in safety culture following the difference in the safety climate (19), in addition, perception of safety signs can reduce unsafe act behavior, eventually reducing relevant industry events (20). Overall assessment of the results shows that there was more consistency in this study than other studies between rate of perception of the safety signs with standards of the international organization for standardization and American national standards institute. The limitations of this study include unwillingness to participate in the study due to false pride of safety signs perception as well as lack of financial ability in determining cultural factors affecting the perception of safety signs.

\subsection{Conclusions}

According to the overall results of this study, assessing the perception of signs shows a moderate level of perception in accordance with the ISO standard. The perception patterns of the safety signs are different. Therefore, according to estimates made, it is recommended that implementation of intervention programs (Judgment test: Effective process participation of workers in the design of safety signs) is due to perceptual adaptation with target population and the redesign of sign with low perception. That safety signs such as "wear a face shield" (s2), "the risk of toxic substances" (s13), and "emergency exit doors" (s7) should be designed according to standards for the industry. 


\section{Acknowledgments}

We would like to sincerely thank the staff and management of the Behbahan faculty of medical sciences for their cooperation and financial assistance in the course of this study and the vital information they provided. The authors declare that there is no conflict of interest.

\section{References}

1. Graphical symbols--Vocabulary. Geneva: International Organization for Standardization; 2003.17724 II.

2. Lesch MF. Warning symbols as reminders of hazards: impact of training. Accid Anal Prev. 2008;40(3):1005-12. doi:10.1016/j.aap.2007.11.009. [PubMed: 18460368].

3. Lesch MF. Comprehension and memory for warning symbols: age-related differences and impact of training. J Safety Res. 2003;34(5):495-505. doi: 10.1016/j.jsr.2003.05.003. [PubMed: 14733983].

4. Liu L, Hoelscher U. International Encyclopedia of Ergonomics and Human Factors, Edition-:. second ed. 3 Volume Set. CRC Press; 2006. Evaluation of Graphical Symbols.

5. Lesch MF. A comparison of two training methods for improving warning symbol comprehension. Appl Ergon. 2008;39(2):135-43. doi: 10.1016/j.apergo.2007.07.002. [PubMed:17900517].

6. Davoudian-Talab A, Meshkani M, Mofidi A, Mollakazemiha M. Evaluation of the perception of workplace safety signs and effective factors. Int J Occup Hyg. 2015;5(3):117-22.

7. Piamonte DPT. Using multiple performance parameters in testing small graphical symbols. Sweden: Lulea Tekniska University; 2000.

8. Shinar D, Dewar R, Summala H, Zakowska L. Traffic sign symbol comprehension: a cross-cultural study. Ergonomics. 2003;46(15):1549-65. doi: 10.1080/0014013032000121615. [PubMed: 14668174].

9. Zamanian Z, Jahangiri M, Norozi M, Afshin A. Comprehension of workplace safety sign: A case study in an industrial company in Shiraz [In Persian]. J Health Safet Work. 2010;1(1):47-52.
10. Zamanian Z, Afshin A, Davoudiantalab AH, Hashemi H. Comprehension of workplace safety signs: A case study in Shiraz industrial park. J Occup Health Epidemiol. 2013;2(1):37-43. doi: 10.18869/acadpub.johe.2.1.2.37.

11. Chan AHS, Han SH, Ng AWY, Park W. Hong Kong Chinese and Korean comprehension of American security safety symbols. Int J Ind Ergon. 2009;39(5):835-50. doi:10.1016/j.ergon.2009.02.009.

12. Graphical symbols - Test methods - Part 1: Methods for testing comprehensibility. Geneva: International Organization for Standardization; 2007. 9186-1 II.

13. Graphical symbols - safety colors and safety signs - part 3: design principles for graphical symbols for use in safety signs. Geneva: International Organization for Standardization; 2006. 3864-3 II.

14. Criteria for Safety Symbols. National Electrical Manufacturers Association; 2008. Z535.3 AA.

15. Piamonte DPT, Abeysekera JDA, Ohlsson K. Understanding small graphical symbols: a cross-cultural study. Int J Ind Ergon. 2001;27(6):399-404. doi:10.1016/s0169-8141(01)00007-5.

16. Arphorn S, Augsornpeug N, Srisorrachatr S, Pruktharathikul V. Comprehension of safety signs for construction workers: comparison of existing and newly designed signs. J Hum Ergol (Tokyo). 2003;32(2):8794. [PubMed: 16022158].

17. Annie WYN, Honour WCL, Alan H. S. C. , editors. Measuring the Usability of Safety Signs: A use of system usability scale (SUS). Proceedings of the International Multi Conference of Engineers and Computer Scientists. 2011; Hong Kong. .

18. Moradi MS, Afshari D, Hoseinzade T, Ahmadi K. Psychological effect of safety signs on message transmission given signs designing features in petrochemical industry [In Persian].J Ergon. 2014;2(2):38-48.

19. Rohollahi A. Investigation of relationship between different dimensions of safety climate with safety performance among aeronautical industries [In Persian]. Iran Occup Health J. 2015;12(3):96-107.

20. Halvani G, Ebrahimzadeh M, Dehghan M, Fallah H, Mortazavi M. Assessment of factors affecting safety culture in Yazd steel industry workers [In Persian]. Occup Med QJ. 2012;4(1):66-72. 